\title{
O "PACOTE" E A ENFERMAGEM (ANÁLISE CRÍTICA DE UMA CENA DE MORTE) ${ }^{1}$
}

\author{
THE "PACKAGE" AND NURSING CARE \\ (CRITICAL ANALYSIS OF A DEATH SCENE) \\ EL "PAQUETE"O Y LA ENFERMERÍA \\ (ANÁLISIS CRÍTICO DE UNA ESCENA DE MUERTE)
}

Claudia Cruz ${ }^{2}$

Regina da Cruz Garofalo ${ }^{2}$

Tatiana Sabino ${ }^{2}$

Maria Aparecida de Luca Nascimento ${ }^{3}$

\begin{abstract}
RESUMO - Estudo descritivo baseado em um relato de experiência de acadêmicas de enfermagem do último período de graduação de uma universidade pública da cidade do Rio de Janeiro. A partir do conteúdo programático da disciplina Abordagens Metodológicas da Pesquisa em Enfermagem II, inserida em um currículo baseado na problematização, as autoras se utilizaram de uma cena de morte ocorrida durante o ensino clínico em um hospital geral público de grande porte, situado na cidade do Rio de Janeiro, para descrever o modo pelo qual este evento vem sendo assistido pela equipe de enfermagem. Tendo como objetivo fornecer subsídios que possam respaldar as reflexões sobre a morte, e à luz do Código de Ética dos Profissionais de Enfermagem, são tecidos comentários a este respeito sob o ponto de vista ético, cultural, religioso e da cidadania. Concluem que o tema morte precisa ser abordado no meio acadêmico, mas não só sob o ponto de vista técnico, pois a interação humana que se estabelece a partir da assistência de enfermagem prevê o cuidado ao cliente durante todo o seu ciclo vital, do qual a morte é a última etapa.
\end{abstract}

PALAVRAS-CHAVE: morte, enfermagem, cuidado

\section{INTRODUÇÃO}

Este estudo surgiu como produto da disciplina Abordagens Metodológicas da Pesquisa em Enfermagem II, que é oferecida durante $07^{\circ}$ período do Curso de Graduação em Enfermagem da Escola de Enfermagem Alfredo Pinto da Universidade do Rio de Janeiro.Nesta disciplina, como forma de avaliação, foi solicitado pela docente que a ministrou um estudo em grupo que versasse sobre um tema interessante, baseado na problematização, relativo a algum aspecto do cotidiano da prática dos discentes em campo de ensino clínico.O objetivo principal era promover a reflexão sobre o tema escolhido, sob a forma de um estudo estruturado metodologicamente

Como a escolha do tema era livre, as autoras optaram pelo tema cuidados "post mortem", não somente por perceberem que esse assunto durante o ensino de graduação prende-se tão somente aos aspectos técnicos que os envolve, como também por correlacionarem

\footnotetext{
1 Prêmio Marina Andrade de Rezende. 1\%ugar, 52० CBEn.

${ }^{2}$ Acadêmicas da Escola de Enfermagem Alfredo Pinto (EEAP) da Universidade do Rio de Janeiro (UNIR/O).

${ }^{3}$ Professor Adjunto do Departamento de Enfermagem Materno Infantil da EEAP da UNIRIO Doutora em Enfermagem - Orientadora
} 
este aspecto do ensino às reações dos profissionais de enfermagem durante a ocorrência de um óbito, cuja cena servirá de apoio para o desenvolvimento do presente estudo.

Deste modo, a motivação para escrever o trabalho foi expressar nossa expectativa como acadêmicas diante da ocorrência de um óbito, considerando os aspectos pessoais, culturais e religiosos que influenciam diferentemente as reações das pessoas frente à morte, tanto no âmbito profissional quanto no familiar.

Lidar com essas percepções, que são baseadas na individualidade de cada ser, perpassa pelo cotidiano da enfermagem porque, sustentando o relacionamento enfermeiro - cliente estão suas aptidões pessoais, culturais e religiosas. Por isso, há necessidade das constantes reflexões sobre a prática profissional, conforme se refere Gauderer, (1995, p.134): "A reação do paciente ou familiares ante uma doença grave ou crônica é muito pouco abordada no nosso meio, menos ainda os sentimentos despertados no profissional que trabalha nessa área".

\section{OBJETIVOS}

- Apresentar subsídios para a reflexão sobre a morte durante a formação acadêmica, a partir da observação de uma cena de morte ocorrida durante o desenvolvimento do ensino clínico.

- Tecer comentários, baseados em suporte bibliográfico, sobre a inadequação do termo "pacote" para denominar um corpo sem vida.

\section{METODOLOGIA}

Estudo descritivo tipo estudo de caso. Esta opção metodológica encontra respaldo em Trivinõs (1992, p. 110) o qual afirma que este tipo de estudo tem por objetivo aprofundar a descrição de determinada realidade.

Deste modo a descrição que serviu de base para o presente estudo foi realizada a partir da observação não participativa de uma cena de morte ocorrida durante o desenvolvimento do ensino clínico da disciplina Enfermagem nas Emergências do Adulto e do Idoso, oferecida pelo Departamento de enfermagem Médico - Cirúrgico da Escola de Enfermagem Alfredo Pinto/ UNIRIO, em um hospital municipal de referência e contra - referência de emergência situado na cidade do Rio de Janeiro

Eis a cena:

Dia 31 de maio de 2000, aproximadamente 15:30 h, último dia de estágio. Como todo acadêmico de enfermagem, estávamos esperançosas em presenciar alguma situação de emergência, esperávamos observar: a atuação dos enfermeiros diante dela. Como seriam desenvolvidos os seus cuidados, como seria a sua postura?

Esta expectativa era acompanhada da visão de que, daqui a pouco tempo, poderíamos estar passando pela mesma situação. Pois bem, entramos na unidade intermediária da emergência, a impressão foi a de estarmos em um setor misto de clínica - médica com CTI. Esta impressão era porque, na nossa visão, um setor de emergência não era sinônimo de um ambiente tranqüilo, organizado e bem equipado como aquele que presenciávamos.

Depois de passarmos por todos os clientes verificando seu estado e quais os cuidados que se faziam necessários, identificamos um cliente recém - transferido para o setor e que, segundo informações da equipe, encontrava - se fora de possibilidades terapêuticas. Seu diagnóstico era de tuberculose, tinha 59 anos.

De repente, notamos uma movimentação exagerada dentro do setor que nos chamou a atenção. Era uma morte... Instalou - se um clima de brincadeira, risos, conversas em voz alta.

Passamos a observar passivamente a cena. A equipe de enfermagem se deslocava rapidamente realizando algumas atividades tais como; enlace dos braços sobre o tórax, 
identificação do cadáver presa ao peito, envolvimento do corpo em um lençol e nova identificação externa. Ao término das atividades ouvimos a menção de que estava pronto o "pacote".

\section{"PACOTE" X CUIDADO “POST - MORTEM"}

Segundo a cena descrita no parágrafo anterior, além da rapidez na execução da técnica do preparo do corpo, observou-se também que os profissionais de enfermagem procederam de forma bastante descontraída para a ocasião, além de terem se referido ao corpo do paciente como sendo um "pacote".

Tendo em vista que, normalmente, por mera reprodução, utilizamos alguns termos sem nos determos nos seus significados, observamos que lingüisticamente o verbete "pacote" é definido como: "pequeno fardo; embrulho" ( Holanda, 1998).

Deste modo, o termo "pacote", que é utilizado freqüentemente no ambiente hospitalar para denominar o corpo sem vida do paciente envolvido em um lençol, após os procedimentos técnicos realizados pela equipe de enfermagem e que se sucedem após a constatação do óbito, ao ser analisado, criticamente, nos mostra sua inadequação ao ser utilizado, pois referese a um cidadão - indivíduo no gozo dos direitos civis e políticos de um Estado (Holanda, 1998) - que é o verdadeiro cliente da enfermagem.

Os procedimentos "post mortem", normalmente, são realizados de forma bastante rápida, de modo a torná-los menos estressantes e, também, possibilitar que o corpo seja retirado do setor onde ocorreu o óbito o mais rapidamente possível.

Considerando a morte como uma etapa da vida, as duas justificativas administrativas citadas acima para que o preparo do corpo seja efetuado de forma rápida, não condizem com a prestação de cuidado preconizada pelo código de ética dos profissionais de enfermagem que em seu Art. $3^{\circ}$, no item que trata dos Princípios Fundamentais, nos diz que:"O profissional de enfermagem respeita a vida, a dignidade e os direitos da pessoa humana em todo o seu ciclo vital, sem discriminação de qualquer natureza."

Seguindo a mesma linha de pensamento, observamos que os direitos da pessoa humana inclui os direitos aos cuidados "post - mortem". Estes cuidados incluem a técnica correta de preparo do corpo e uma atitude de respeito por parte da equipe de saúde.

\section{A MORTE E SEUS RITUAIS}

"A única certeza que temos na vida é a de que vamos morrer...". Quantas vezes já ouvimos esse dito popular. A morte é um fenômeno inerente à vida e por esta razão todos estão sujeitos a ela. Quando falamos em morte e rituais, não podemos deixar de considerar a cultura como base para toda e qualquer manifestação de pesar. Há que se considerar que a "cultura " é o complexo dos padrões de comportamento, das crenças e de outros valores espirituais e materiais transmitidos coletivamente e que são característicos de uma sociedade". (Holanda, 1998 ).

Por isso, antes de julgarmos as atitudes que nos incomodam devemos analisar em que contexto elas estão inseridas. Por exemplo, os parses ( religião indiana ) expõem os corpos de seus mortos nas chamadas " torres de silêncio " para serem consumidos por abutres e outros pássaros (ENCICLOPÉDIA ISTO É, 1993). O que para nós seria uma cena pavorosa, para eles é uma maneira de não contaminar o solo, o fogo e nem a água. Outro exemplo, na lei judaica o corpo é enterrado em solo consagrado após ser lavado, ungido com ervas aromáticas, envolvido em um lençol branco e colocado em uma caixa simples de madeira. Durante os funerais, as pessoas de luto rasgam as suas próprias roupas.

Na nossa sociedade várias culturas se misturam mas, os sentimentos de pesar e tristeza durante os funerais são as atitudes que prevalecem. 
O fundamental para a enfermagem é fazer com que, independente das culturas e seus rituais, sejam respeitados os direitos de cidadão de seus clientes, pois, de acordo com Germano (1993, p.75), ao se referir à assistência de enfermagem ao paciente em iminência de morte:"(...) essa difícil tarefa que extrapola a relação direta enfermeiro/paciente, estendendo-se também à família, exige nos dias atuais uma reformulação dos sentimentos de cada profissional sobre a morte e o morrer e mesmo a respeito da vida."

\title{
CONCLUSÃO
}

De acordo com o que vivenciamos em nossa vida acadêmica, podemos afirmar que os enfermeiros não estão preparados para a morte de seus clientes. Fazemos esta afirmação pois poucos são os momentos nos quais a morte é discutida, tanto no meio acadêmico quanto no meio profissional, a partir das reações que provoca.

Normalmente, as discussões acadêmicas restringem-se ao conteúdo técnico que a morte determina.

Devemos demonstrar nossa angústia e pesar quando da morte de um cliente uma vez que estamos interagindo com ele durante todo o tempo em que prestamos nossa assistência. Afinal, somos pessoas e como tais possuímos sentimentos e emoções e acreditamos que expressá-las de forma respeitosa implica em potencializar o cuidado de enfermagem ao cliente, pois esta é a profissão que acompanha o ser humano através de todo o seu ciclo vital, que termina com a morte.

Para que isso ocorra é preciso preparar os profissionais nos centros de formação para lidarem com a morte, não apenas tecnicamente, mas emocionalmente, também, embora saibamos que sempre será difícil viver este momento, pois sob qualquer ponto de vista; profissional, pessoal, cultural, estaremos lidando com a sensação de perda de um ser humano. Porém, é necessário abordar o tema morte sob os mais variados aspectos, a partir de diferentes contextos e problematizações. Segundo Germano (1993, p.77):“...parece existir um consenso em torno da falta de preparo do enfermeiro e dos demais profissionais de saúde na atenção à morte"

Deste modo, podemos dizer que os cuidados de enfermagem "post mortem", exigem cautela, postura, ética e, acima de tudo, respeito. Pois, para que realmente possamos prestar uma assistência de enfermagem numa visão holística da qual a morte é a última etapa, precisamos, como ponto de partida, entender que nenhum ser humano se transforma em "pacote" após a sua morte.

\begin{abstract}
This is a descriptive study based upon an experience related by a group of nursing students in their senior year at a public university in the city of Rio de Janeiro. As part of a course content in Methodological Perspectives in Nursing II, based on problem solving, the authors analysed a death scene which occurred during practical training, in a large public general hospital, in order to describe how nursing staff deal with such an event. The main goal of the study was to provide thought provoking material from different points of view - cultural, religious and ethical - concerning the subject of death and the professional nursing ethics code The authors concluded that the such a theme must be discussed in the academic environment, but not only from a technical point of view, for the process of human interaction which is established during health assistance demands the provision of nursing care to the patient during his entire lifespan, of which dealth is the last stage.
\end{abstract}

KEYWORDS: death, nursing, care

RESUMEN: Estudio descriptivo basado en un relato de experiencia de académicas de enfermería del último año del curso en una universidad pública de Rio de Janeiro. A partir del contenido programático 
de la disciplina "Perspectivas Metodológicas de la Investigación en Enfermería II", dentro de un currículo basado en la problematización, las autoras utilizaron una escena de muerte que había ocurrido en un hospital general público en la misma ciudad de Rio de Janeiro, con objeto de describir cómo ese evento se viene asistiendo por el equipo de enfermería. Todo ello para obtener subsidios que puedan respaldar las reflexiones sobre la muerte, bajo el Dódigo de Ética de los Profesionales de Enfermería y tejer consideraciones al respecto bajo un punto de vista ético, cultural, religioso y de ciudadanía. Se concluye que el tema muerte se tiene que tratar en el medio académico, pero no sólo bajo el punto de vista ténico, pues la interacción humana que se establece a partir de la asistencia de enfermería prevé el cuidado al cliente durante todo su ciclo vital, del cual la muerte es la última etapa.

PALABRAS CLAVE: muerte, enfermería, cuidado

\section{REFERÊNCIAS BIBLIOGRÁFICAS}

IISTO É, Enciclopédia Compacta - Guinness de conhecimentos gerais. São Paulo: Três, 1993.

GERMANO Raimunda Medeiros. A ética e o ensino de ética na Enfermagem do Brasil. São Paulo: Cortez, 1993. 141p.

HOLANDA, Aurélio B. de . Dicionário Aurélio Básico da Língua Portuguesa.Rio de Janeiro: Nova Fronteira, 1998.

TRIVIÑOS, Augusto N.S. Introdução à Pesquisa em Ciências Sociais. São Paulo: Atlas, 1992. 175p.

GAUDERER, E. Christian. Os direitos do paciente. Rio de Janeiro: Record, 1995. 223p. 